$\$$ Research Square
Preprints are preliminary reports that have not undergone peer review.

They should not be considered conclusive, used to inform clinical practice, or referenced by the media as validated information.

\title{
Health Research Capacities in Palestine: High-quality and Proper Knowledge Transfer and Translation for Sound Decision-making
}

Mohammed AlKhaldi ( $\nabla$ moh.khaldi83@gmail.com)

Universitat Basel, Swiss Tropical and Public Health Institute-Switzerland, Najah National University-Palestine https://orcid.org/0000-0003-

1224-8102

Hamza Meghari

University College London Institute for Global Health

Irene Anne Jillson

Georgetown University School of Medicine

Abdulsalam Alkaiyat

Al-Najah National University

Marcel Tanner

Universitat Basel

Sara Ahmed

McGill University Faculty of Medicine

\section{Research}

Keywords: Health research system, capacities, research quality, transfer, translation, Palestine

Posted Date: January 23rd, 2020

DOI: https://doi.org/10.21203/rs.2.21662/v1

License: @ (1) This work is licensed under a Creative Commons Attribution 4.0 International License. Read Full License 


\section{Abstract}

Background: Over the last two decades, the World Health Organization (WHO) has proposed a global strategy and initiatives to build robust capacity for a Health Research System (HRS) focusing on Health Research Quality and Standardization (HRQS), Health Research Knowledge Transfer and Dissemination (HRKTD), and Health Research Translation and Utilization into Health Care Decisions and Policies (HRTUDP). Despite the expansion of health research productivity for several decades, HRS Capacity (HRSC) in Palestine and in the Middle East and North Africa (MENA) region generally has rarely been objectively evaluated. This study aims at eliciting the perceptions of HRS performers in Palestine in order to understand the status of the capacities of HRS, identify gaps, and to generate policies and solutions capable of strengthening HRSC in Palestine.

Methods: Purposive methods were used in this qualitative study to identify key informants from three sectors; government, academia, and local and international organizations. Fifty-two in-depth interviews were conducted with key informants and a total of fifty-two individuals participated in six focus groups. Data were analyzed by using MAXQDA 12.

Results: The overall pattern of the Palestinian HRS capacities is relatively weak. The key findings revealed that while HR productivity in Palestine is improving, HRQS is at an average level and quality guidelines are not followed due to paucity of understanding, policies, resources. HRKTD is a central challenge with both a dearth of conceptualization of translational science and inadequate implementation. The factors related to inadequate HRKTD include lack of awareness on the part of the researchers; inadequate regulatory frameworks and mechanisms for both communication and collaboration between and among researchers and policy-makers and clinicians; lack of availability of and credibility in systematized and reliable HR data. Despite the limited knowledge translation, in general, HRTUDP is not considered as an essential decision-making methodology mainly due to lack of knowledge producers and policy-makers interface, understanding level, HR credibility and availability of applied research, and governance, resources, and political fluctuations. A consolidating regulatory framework and an effective capacity strengthening strategy to promote HRQS as well as an understanding of concepts and practices of translational science and, most importantly, the use of findings for evidence-based policies and practice are substantial recommendations to make HRS wellcapacitated and strengthened.

Conclusions: Strengthening HRSC is both an imperative step and an opportunity to improve the Palestinian health system based on research evidence and knowledge. Building a successful HRS characterized by capacities of high-quality research and well-disseminated and translated knowledge is a prerequisite to effective health systems and services. This can be achieved by a political commitment to support such strengthening, consolidated leadership and governance structure, and a strong operational capacity strengthening strategy.

\section{Background}

Health research (HR) has been recognized as an essential tool in addressing health and development challenges, yet the current capacity of many developing countries to conduct relevant and high-quality, rigorous $\mathrm{HR}$, and disseminate and translate findings into practices remains limited $[1,2]$. The knowledge produced by HR is a global public good, indispensable for improving the health of individuals and populations, developing evidence-informed policies and enhancing the performance of health systems (HSs) $[3,4]$. For the establishment of such a Health Research System (HRS), it is crucial that nations develop and sustain the capacities necessary to produce research, disseminate findings, apply them in policy and practice, and to evaluate the impact of research on health outcomes [5]. According to the framework of Pang et al., the aims of a $\underline{\mathrm{HRS}}$ are to advance scientific knowledge and ensure the use of knowledge to improve health and equity. There is broad consensus among the community of science that high-quality knowledge should be generated and appropriately transferred and translated to support health decision-making and policy formulation, contributing to effective and efficient decisions by planners and policy-makers and professionals $[2,4,6]$.

Consequently, HR quality and standardization (HRQS), HR knowledge transfer and dissemination (HRKTD), and HR translation and utilization into decisions and policies (HRTUDP) are the key operational and functional capacities of a HRS. The three capacities that are fundamentally featured in conceptual HRS frameworks compose a solid base for building and advancing any HRS [7-10]. These frameworks serve as a basis for understanding HSs through a wide-range analysis [11-13] and strengthening these capacities from a system-wide approach, as other similar studies showed [14-17]. Evaluating and strengthening the capacities of a HRS are essential to improve health outcomes and address global health challenges not only in developing countries but also worldwide [14, 18].

HRS capacity strengthening (HRSCS) is an ongoing process. Certain efforts to strengthen the HRS capacities, supported by the World Health Organization (WHO), the Council on Health Research for Development (COHRED), the Global Forum on HR and other agencies, underline this process explicitly $[19,20]$. However, HRSCS remains one of the world's unmet challenges in developing countries [20] in particular in the context of the 10/90 gap; that less than $10 \%$ of global resources for HR addressed health problems in developing countries, where over $90 \%$ of preventable deaths occurred [21]. The 10/90 gap, having essentially remained the same nearly three decades after the gap was first identified, 
has significant consequences; not only is HRSC not strengthened in low-resources countries, but there are, as a result, relatively relevant findings of major gaps in HRSC can also be applied to policy processes, clinical practices, and monitoring and evaluation of research results and outputs generally and in sub-Saharan Africa [22].

HRSCS strategy has been implemented worldwide to address these gaps in order to improve the ability of developing countries to overcome the persistent and disproportionate burden of disease that they face. Notably, although the terms "capacity strengthening" and "capacity building" are often used interchangeably, there is a distinction; the first referring to establishing a research infrastructure, while the second denotes enhancing a pre-existing infrastructure [23]. The strategy has gained substantial attention where donors have invested in a capacitystrengthening strategy and are therefore increasingly interested in evaluating the benefits of their investments in HR [7]. Globally, different initiatives and efforts have highlighted the importance of HRSCS through collaboration and harmonizations [14]. The ESSENCE initiative is an example of collaboration, allowing donors/funders of HRCS to identify synergies, establish coherence, and increase the value of resources and action for HR. This paper suggests that embracing the framework of HRSCS is useful along with the adopted frameworks of a HRS.

Across the Middle East and North Africa (MENA) region, HR faces critical deficits in governance, resources, and capacity in terms of knowledge production, dissemination, and application [11, 22]. Similar deficits exist in Palestine; insufficient knowledge, for example, sheds light on the reality of HR capacities. Although HR production is increasing [24], the extent of its capacity is still an unexplored challenge and constitutes an issue of concern [15-17, 24-26]. Understanding the HRSC is a central step towards strengthening the following key elements: the abilities of individuals, institutions and country to perform HR functions, defining national priorities, solving national health problems, utilizing the results of HR in policy-making and programme delivery [22]. Furthermore, because Palestine is an external aid-dependent country, it faces the challenge of the inadequate role of local and international stakeholders to support both HR capacity strengthening of individuals and institutions and support of HR itself. The role of donors needs to be promoted and harmonized and any resources and aids should be effectively used [27-29].

This study of HRSC in Palestine, which is consistent with WHO's strategic directions on HRS development, could also inform plans for the strengthening of HRS capacities at the regional MENA level. It aims at understanding and exploring the status of HRS capacities in Palestine in order to identify gaps and solutions, thereby strengthening HRS. Moreover, this is the first study to explore HRSCS in Palestine and to outline a clear and comprehensive plan for building a sustainable and rigorous national HRS that is well capacitated in Palestine. A vital assumption of this study is that building or strengthening HRSC in Palestine is an investment decision and an opportunity that will advance not only health but also other development sectors.

Specific objectives:

1. Assess the actual status, gaps, and opportunities of the HRS capacities in Palestine.

2. Examine HRS potential to recognize the three vital capacities and competencies: HRQS, HRKTD, and, ultimately, HRTUDP.

3. Generate more insights and solutions to improve the HRSCS and address its gaps.

\section{Methods}

This study is part of a more comprehensive systems analysis. The design, methods, and instruments used were typically similar to local studies that dealt with other components of HRS and have been carried out in Palestine. Participants were purposively selected from three sectors in the health field including governmental health institutions, schools of public health, and major local and international health agencies. The approach of collecting, managing, and analyzing data through conducting 52 in-depth interviews (IDIs) and 6 focus group discussions (FGDs) was also typically adopted and used in previous similar qualitative studies in Palestine [15-17].

\section{Results}

The overall responses were obtained from 104 experts who are involved in the HRS. Apart from the socio-demographic characteristics of the participants that were previously presented in other relevant studies, the responses covered findings in three key areas of HRSCS:

- Health research quality and standardization (HRQS).

- Health research knowledge transfer and knowledge translation (HRKTD).

- Health research translation and utilization into decisions and policies (HRTUDP).

\section{Quality and Standardization in Health Research}


Table 1 compares the pattern of HR in Palestine against the best quality practices and standards of international research. Findings are rather diverse and were categorized into two groups. The first group of experts perceived that HR standardization, guidelines, and quality in Palestine are satisfactory and considerably improved, this is clearly outlined by one government participant: "yes, at the publishing stage where international journals have rigorous guidelines". The perceptions of the second group viewed HRQS as on a less than satisfactory level, and they considered this issue a big gap and a serious problem. This is clarified by an NGOs expert, who said: "there is an immense number of HR with a lack of quality".

The findings indicate that the most frequent gaps facing HRQS can be sorted into two groups; (1) institutional and environmental gaps; and (2) gaps related to research and researchers. The first includes the lack of HR policies and priorities, resources and capacity, the lack of specialized excellence research centres, and weak institutional review of research. The second group of gaps comprises lack of researchers' culture and attitude and linkage with the international research landscape, the scarcity of articles published in prestigious high-impact local journals and access difficulties, the weakness of curricula in university health sciences education, and research individualism of research activities.

The respondents collectively identified five recommendations to strengthen HRQS:

(1) Strengthening political will to support agreed-upon HR policies and priorities, with a focus on the quality of HR.

(2) Mechanisms should be developed to facilitate greater openness to international HR expertise, strengthen partnerships, and exploit the technology and communication facilities for exchange programmes.

(3) Systematic capacity building and education programmes to increase stakeholders' knowledge and competencies about fundamental topics of good HR quality such as design, methods, analysis, writing, and publication and dissemination.

(4) Provide support for the HR teamwork and invest in existing research initiatives such as The Lancet Palestinian Health Alliance (LPHA), which, as an excellent platform, encourages all HR in Palestine to be rigorously designed, implemented, reviewed, and disseminated. And:

(5) Establish a national monitoring and evaluation mechanism for HRQS.

\section{Health Research Knowledge Transfer and Dissemination}

Table 2 presents the findings for the capacity for HR knowledge transfer and dissemination (HRKTD). The study identified agreement among the respondents concerning HRKTD, with three themes emerging from the data; (1) the main hindrances to HRKTD, (2) improvements, and (3) prospects to be invested. IDIs and FGDs consistently showed a consensus on the unsatisfactory level of HRKTD and non-systematic and ineffective sharing of evidence, with noticeable descriptions including, for example, the following: "completely dissatisfied", "not performing well and below the required level", "barely transferred or shared", "almost paralyzed", and "poor and limited". Participants in government FGDs described the HRKTD in negative terms, with HR outputs unused and remaining "on the shelves". Another small number of participants, mainly academics and government experts, expressed that the HRKTD pattern is often good and growing.

Six gaps were identified by experts concerning HRKTD:

1. The lack of a regulatory framework, policy, resources, and poor communication and coordination between producers and users with very weak international networking.

2. Gaps related to the process, such as the immature culture of sharing and lack of tools and mechanisms, particularly with regard to conferences, local journals, periodicals, workshops, libraries, and platforms. Moreover, HRKTD is selective but non-inclusive, meaning that it is limited to micro-institutional and individual levels but not endorsed or practised in the national policy sphere.

3. HR is carried out for researchers' personal purposes and/or donors' very specific agendas; that is not necessarily addressing the needs of the Palestinian health sector and population.

4. HR is an incomplete performing process, from the inception of a research idea to the translation of the outputs, and the role and skills of researchers in the dissemination and translation are lacking.

5. Decision-makers' rely on their internal reporting systems; they are not well evidence-oriented and, thus, the concept of evidence-based decision-making is not practised.

6. Data inaccessibility, a high degree of disorganization, and a tendency to the monopolization and control of the data collected by researchers or inability to share the national vital statistics and data with everybody in a transparent and systematic manner, as well as blockages and barriers due to political instability. 
To address these barriers, respondents made some suggestions to advance HRKTD. The most substantial action is obtaining political support to establish a national body to guide HR policy, to mobilize resources, to delineate roles of stakeholders, and to enhance coordination. It is also necessary to increase the awareness and skills of researchers and decision-makers regarding HRKTD. They suggested, for example, to:

- Apply technology and interactive facilities;

- Invest in advancing HRKTD mechanisms and tools to enable both science and decision-making communities, to meet for a sustained and reciprocal dialogue focusing on the centre for Knowledge to Policy (K2P), the Strategic Policy Platform, and the Research-Decisionmaking Lab;

- Ensure that the information and databases systems are organized, accessible, and transparent; and

- Encourage and support a spirit of research teamwork and incentives to encourage publication.

Interestingly, the experts suggested opportunities that, if utilized, will foster the advancement of the HRKTD process; these included for example: the availability of abundance of published and unpublished research by Palestinians, existing partnerships, active HR bodies and organizations, excellent experts and students, and relevant academic research flagships or initiatives such as Palestine 2030-Demographic Change: Opportunities for Development.

\section{Health Research Translation and Utilization into Decision and Policies}

This last section explores the pattern of HR translation and utilization into decisions and policies (HRTUDP) in the Palestinian health sector. As Table 3 illustrates, there was a considerable concordance among experts' perceptions expressed in both IDIs and FGDs: that the outputs of HR are not inherently and consistently applied and relied upon in the decision-making process. From their perspective, the spectrum of echoed descriptions ranged as follows: HR in Palestine has "no application", is "weak and poorly-translated", "disappointing", "un-embedded", "ineffective and inappropriate", "producer-user huge gap", "improper KTD", "HRTUDP received executive's inattention and it is not a tool in decision-making", "HRTUDP is unmet issue", and "most of the decisions are not evidence-based". On the other hand, a limited number of participants believed that there are known practices to effectively translate research findings to policies and practices in Palestine. These practices are carried out on an individual, selective, occasional, and much interest-driven, as well as not well-structured way in the health decision-making process. However, very few experts expressed their lack of knowledge and awareness about the HRTUDP and its implementation.

The study found critical gaps that adversely affect the translation of HR findings to policy and practice. These gaps are divided into three categories according to the prominence in the responses: (i) conceptual, (ii) technical and (iii) gaps related to the health system and HRS at large. Conceptually: for decision and policy-makers are not yet research-oriented, with a lack of knowledge and culture of evidence-based decision (EBD) and knowledge-informed policy (KIP). Technical gaps revealed major communication and coordination gaps between researchers and decision-makers. There were poor KTD and data sharing mechanisms and tools; issues such as HR quality and credibility; the fact that research carried out by individual researchers does not reflect crucial national priorities; plenty of descriptive HR but a paucity of public investment in applied and experimental research; and HR produced by academics does not receive serious state attention. The last group of shortcomings of HCS and HRS were the absence of a unified regulatory framework; absence policy, and priorities; lack of resources dedicated to HR; institutional instability and management changes; and national political and economic conditions such as financing restrictions, blockage, loss of sovereignty.

For the initiation of a dynamic process for knowledge transfer and translation in decision-making and policy formulation of the health system, respondents recommended different proposals that fall into two categories: structural-policy and technical-procedural. The first refers to the need to create a regulatory framework that includes unified policy and priorities ensuring effective communication across all stakeholders and to build local (state-academic integration) and international partnerships to make HRTUDP functionally applied. In addition, political influence on the decision-making and planning process should be prevented. For the technical-procedural track, it is indispensable to:

(1) Ingrain the concepts, practices, and tools of HR, EBD, and KIP among decision-makers across sectors and also the concepts and approaches of KTD among researchers, as other studies clearly emphasized [15-17];

(2) Create dynamic communication channels between the research and policy communities through knowledge-policy forums or centres, journals clubs, policy workshops, and national policy briefs and summaries; and

(3) Encourage dissemination and distribution of research and knowledge through creative technological-institutional and national well-linked channels. 
Lastly, the most important enabling opportunities to be exploited are existing bodies, initiatives, and previous attempts to push towards developed and capable HRTUDP, among them: the Palestinian National Institute of Public Health (PNIPH), The Supreme Palestinian Health Council (SPHC); Scientific Research Council (SRC); Palestinian Council for Health Research (PCHR), the Lancet annual conference, Lancet Palestinian Health Alliance (LPHA) and other relevant stakeholders.

\section{Discussion}

This study dealt with one of the most important pillars of the HRS [30]; exploring the system's capacities. As the HRS exists in a complex and diverse context [31,32] and is of increasing concern to health policy-makers, providers, and others [7, 9, 33], the findings of this analysis are expected to offer a contribution to the understanding of capacity components of the HRS in Palestine. This, in turn, will increase the potential for a successful and effective HRS based on active participation and well-strengthened capacity.

The findings of this study indicate that the level of research quality and compliance with good HR standards is still insufficient and needs more attention. A previous study found that in Palestine the subject of HR capacity is under the satisfaction level [26], although research quantity in the MENA region is not only increasing, the quality of HR is also improving [34]. The reasons for the low level of HR quality and non-compliance with HR standards can be related to institutional and environmental challenges. These includes namely, the lack of cohesive policies and priorities; capacity and resources, and institutional quality and ethical reviews, as one study proved [16]. Other gaps are caused by the lack of researchers' knowledge and international exposure to HR quality standards and expertise. This, however, has been refuted by a study which indicated that international collaboration in research output was clearly reported [24]. Moreover, the shortage of trusted and highquality local journals, individualism instead of interdisciplinarity in HR production, and, more importantly, a severe lack in basic research subjects will have to be tackled inherently by the health schools' curriculum.

The analysis of participants' responses across both methods revealed four practical steps that may improve HRQS:

(1) A national policy that prioritizes the quality of HR.

(2) Technological mechanisms such as interactive electronic platforms and hubs that can link external HR knowledge and expertise with the local HR community [24].

(3) The creation of guidelines for improving HRQS and embedding of these guidelines into health schools' curricula and also integrating them into capacity building programmes to develop researchers' skills and capabilities. One example is the CONsolidated Standards of Reporting Trials (CONSORT) [26].

(4) Strengthening HR ethical and technical review, evaluation, and follow-up [16]. Embedding such foci in the education and training of health researchers is a central action for increasing the quality value of HR in Palestine.

The current study further evidently revealed a number of constrains to HRKTD. These include, for example, the fact that knowledge generally, and research outputs in particular, are not disseminated regularly and appropriately. As a consequence, the evidence diffusion process remains weak mainly due to inadequate utilization and demand for research [35]. A comparable study showed that building HRSs to support HRKTD for improved health is one of the major challenges across the region [11].

Several impediments to good practice of HRKTD were identified; these include:

- Shortage in the culture of HRKTD among seniors at the high-management levels and research managers and researchers on HRKTD or evidence-informed policy-making concepts, and even HR culture [17,36].

- HRKTD mechanisms and tools are lacking such as platforms, forums, peer-review journals, press releases, policy briefs, and libraries such as recommended by HINARI [37] and WHO [38]. HRKTD practices are, furthermore, often limited to the micro-institutional and individual levels, rather than through a systematic and inclusive national approach [35].

- HR is carried out for personal purposes or for donors' agendas, with the result that the publication and dissemination of findings are often either missing or neglected.

- This study as well as others emphasized the absence of a regulatory framework such as body and policy, inadequate resources, and local and external poor coordination; this creates confusion in HR production, dissemination, and utilization. Finally:

- Difficulties related to data quality and availability, whether vital national statistics or data collected from HR, as well as the conditions of borders blockage and movement obstacles that prevent the flow of researchers and materials to and from Palestine. Another study added further gaps. such as the low level of engagement in the HRKTD activities due to the little support available in the HRKTD environment, including the lack of incentives [35]. 
For better HRKTD, as highlighted previously in the HRS stakeholder analysis part, there is a need to increase the involvement of the political level and advance a regulatory framework for HR. This move should make it possible to define the stakeholders' roles, to improve coordination and the concepts of HR and HRKTD among decision-makers and researchers alike [4, 11, 35, 39]. More investment is necessary to establish HRKTD strategy including innovative tools using technology, for example, a national archive for science data [37], national platforms such as KIP [40], K4P, strategic policy platforms, or research decision-making centres or labs. This strategy should embrace the helpful WHO model for HRKTD [38]. A strengthening of Palestinian national and institutional databases is needed to improve quality, organization, accessibility, and transparency, and enhance the local and international partnerships and collaboration in HR production and dissemination [7].

The study found HRTUDP a central concept emphasized by the WHO Eastern Mediterranean Regional Office (WHO-EMRO) in its strategic directions for research for health, a pivotal tool for health development and informing health policy improvement [35]. HRTUDP was first demonstrated by the Canadian Institute of Health Research (CIHR) to bridge the knowledge-practice gap and is being now widely used with interchangeable terms in the literature (e.g. knowledge transfer, research utilization, evidence implementation) [41]. HRTUDP in Palestine exists under constrained circumstances and has, so far, not been a key tool in the decision-making process in the country's HCS. This study identifies knowledge and policy gaps and it recommends to enhance the research-policy interface [35]. The problem of an unsupportive culture for research to become acknowledged should be addressed, where decisions or policies are mostly not evidence- and knowledge-based, and decision-makers are not knowledge-oriented [42]. This is also consistent with AlKhaldi et al., on the deficient conceptualization level on HR or HRS at large [17]. In return, a study carried out in the region denies the presence of negative attitudes among policy-makers towards research evidence, its use, and benefits in practice, and it calls for fostering evidence-informed policy-making by establishing a clear understanding of the national context in which policy decisions are made [35].

Other identified technical constraints are a deficit in trust and inconsistent relations [43] between the knowledge-producers and the decisionmakers, which weakens knowledge diffusion. Moreover, academic knowledge production was found to be an area of low investment by the state. A further limitation related to HR quality and credibility is HR deficiency in addressing real priorities with plenty of descriptive studies compared to a paucity of experimental studies, which offer evidence that is more trustworthy. This is clearly emphasized by a similar study [44]. Finally, with the absence of good HR governance, policies, and priorities, scarcity of resources, and institutional management changes, and political instability as literature demonstrated [8, 23, 35, 45-47], knowledge and research-informed policy-making will remain impossible unless these fundamental hindering issues are addressed. Therefore, substantive structural and technical-procedural changes should be implemented to promote knowledge translation and decision-making practices and to eliminate preference-based decisions, whereby the health systems could eventually be strengthened $[43,48]$.

These are the changes and improvements suggested:

First: Urgent synergized efforts to establish a well-structured HRS, involving and organizing all HR components, including HRTUDP. This is largely consistent with the debate at the Global Forum 2015 which attributed the low uptake of evidence partly to weak governance and suboptimal collaboration and engagement among research, industry, policy-making, and community societies [43].

Second: The concept of HRTUDP and evidence and knowledge-based practices, as others such as HR, HRS values, goals, and stewardship functions, HRQS, and HRKTD concepts, need to be entrenched among the health system's decision-makers and researchers.

Third: Building knowledge translation strategies consisting of effective communication channels and interactive integration spaces mandated by $\mathrm{MoH}$ and academia, as proposed in HRKTD, such as national HR or knowledge-policy networks, forums [40], models [51], journals, labs, Hackathons, centres, clubs, policy briefs magazines, and media releases [38, 43]. Fourth: Maintaining synergy and dynamic mechanisms between HRTUDP and HRKTD as both complement each other [44].

Fifth: On top of that, capacity building and education programmes on HRKTD should be provided in collaboration with local and international partners. In Palestine, some active bodies, such as local universities, PNIPH, and different initiatives, such as LPHA, are likely to be driving forces to achieve that.

The study limitations can be summarized as follows:

(1) The substantial knowledge gap of relevant literature on the subject as well as the lack of dada availability, quality, organization, and accessibility;

(2) Time constraint for an even more comprehensive analysis, linked to the restrictions on the freedom of movement of the research team as a result of the closure and security checkpoints; and

(5) The constant environmental and political fluctuations and institutional changes. 
Consequently, the present study proposes further research in the following key areas:

1. A national need assessment study or quantitative study may be useful to precisely determine and assess the HRSC currently available such as practices, assets, resources, and facilities at the individual, institutional and national levels.

2. There is a need to examine, perhaps by using observation or case study methods, specific knowledge transfer and application practices.

\section{Conclusion}

There is a growing global and regional concern about advancing the core capacities of HRS, HRQS, HRKTD, and HRTUDP. These capacities relate to the ultimate goal of the HRS, which is the generation of scientific knowledge and the promotion of this knowledge to improve HS performance, achieve Sustainable Development Goals (SDGs), and ensure the healthy lives and well-being of the population. The process of HR and knowledge production starts with designing and implementing rigorous decision-relevant research; publishing and sharing its outputs; and translating these outputs into health policy interventions and practices. To achieve this, there is an emphasis on the need to build wellfunctioning HRS. This system needs to be strengthened through deep analysis and understanding of the system's pillars, mainly HR quality and knowledge transfer and translation.

The study has a significance stemming from the importance of the subject under investigation, which has only minimally been assessed in Palestine and in the MENA region. The study offers an in-depth description of the current pattern of the three key capacities, the identification of the major gaps hindering the advancement of HRS capacities, and suggestions to strengthen the three capacities of HRS in Palestine. This study could be an essential scientific reference,a fresh research attempt to draw the attention of local and regional health decision-makers, health professionals, and researchers. In summary, the study revealed that the overall pattern of Palestinian HRS capacities is characterized by considerable systematic weakness. The issue of HRSCS deserves to be of high priority for the state and non-state stakeholders where it should be enabled on individual, institutional, and national levels.

The study concludes that there are strong opportunities to invest in the capacity of HRQS. Research productivity in Palestine is increasing while HR quality is poor due to guidelines which are not being followed. Weaknesses in policies, resources, institutional capacity, and individual orientation, as well as in the education curricula are at the bottom of the low level of HRQS. A national policy, which embeds and institutionalizes international guidelines in the setting of teaching, research, and practice, develops education programmes and improves professionals' and researchers' understanding of research quality topics and also promotes its capacity and resources at the individual, institutional, and national levels is imperative.

HR and knowledge outputs do not disseminate properly and systematically due to lack of regulatory framework, a low understanding level and culture among seniors and researchers on knowledge sharing and transfer, shortage of HRKTD mechanisms and coordination means, lack of data quality and availability, and environmental restrictions. Political participation, HRKTD strategy and communication mechanisms such as establishing a national observatory or platform for both HRKTD and HRTUDP, and local and international partnerships are substantial actions for successful, dynamic HRKTD. HRTUDP, as a central concept for health development and policy improvement, is remarkably constrained in Palestine and it is not an essential decision-making methodology. Knowledge producers' and users' disconnection, culture, HR credibility, applied research, and governance and resources and management and political changes are behind ineffective HRTUDP, where an organizing framework, entrenching its concepts and strategies and mechanisms and structurally linked with HRKTD needs to be implemented. Ultimately, although our study is specific to the Palestinian case, implications for the wider context are apparent and particularly relevant for developing countries and the MENA region. There is a need to reemphasize the perspective of thinking outside the box by focusing on strengthening HRS capacity to ensure good practice for high-quality knowledge and evidence uptake in Palestine and in the region. Actions identified in this study, whether at the individual, institutional, country, or regional level or beyond, should be addressed through political commitment, national consensus, a unified governing structure and system and HRSCS strategy as well as partnerships and collaboration.

\section{Abbreviations}

CIHR: Canadian Institute of Health Research; COHRED: Council on Health Research for Development; CONSORT: Consolidated Standards of Reporting Trials; EBD/EBP: Evidence-Based Decision/Evidence-Based Practice; EKNZ: Ethikkommission Nordwest- und Zentralschweiz; FGDs: Focus Group Discussions; HR: Health Research; HRKTD: Health Research Knowledge Transfer and Dissemination; HRQS: Health Research Quality and Standardization; HRS: Health Research System; HRSC/HRSCS: Health Research System Capacity / HRS Capacity Strengthening; HRTUDP: Health Research Translation and Utilization into Decisions and Policies; IDIs: In-depth Interviews; K2P: Knowledge to Policy; KIP: Knowledge-informed Policy; LPHA: Lancet Palestinian Health Alliance; MENA: Middle East and North Africa; MoH: Ministry of Health; NGOs: Non-governmental Organizations; NNU: Najah National University; PCHR: Palestinian Council for Health Research; PNIPH: Palestinian National Institute of Public Health; SPHC: The Supreme Palestinian Health Council; SRC: Scientific Research Council; STPH: Swiss Tropical and Public Health Institute; WHO/EMRO: World Health Organization / Eastern Mediterranean Regional Office. 


\section{Declarations}

\section{Ethical approval}

The Research Commission of Swiss TPH approved the study (FK No. 122; approval date: 21 October 2015). Ethical approval was obtained from the "Ethikkommission Nordwest- und Zentralschweiz" (EKNZ) in Switzerland (reference No. UBE-15/116; approval date: 23 January 2016). Ethical and administrative approval from Palestinian MoH obtained on 28 April 2016, the institutional review board of Helsinki Committee in Palestine (reference No. PHRC/HC/73/15; approval date: 7 December 2015), and the institutional review board (IRB) at NNU (reference No. 112/Nov./2015, approval date: 6 December 2015).

\section{Consent for publication}

Not applicable

\section{Availability of data and materials}

To keep data protected, data from the experts through interviews and FGDs are saved on the principal investigator's official laptop. These data are stored in a highly secured laptop with a secured key-file entry, under the control of the principal investigator MK and the supervisor MT, and only these two together have the right of accessibility and to review and use these data.

\section{Competing interests}

The authors declare that they have no competing interests.

\section{Funding}

This work is jointly sponsored by the Swiss Federation through the Swiss Government Excellence Scholarships for Foreign Scholars and the Swiss TPH. The second sponsor had a role in scientific and technical consultation and guidance. This work has been completed through a research grant provided by the Quebec Research Fund in Canada in a collaboration with McGill University.

\section{Authors' contributions}

MT, HM, IJ, AA, MK, and SA contributed to the conception and methodological design. MK, HM, and AA contributed to the collection and analysis of data. MK and HM contributed to the interpretation of the results and the drafting of the manuscript. All authors mentioned contributed to technical enrichment and the writing and also reviewed, and then approved the final manuscript.

\section{Acknowledgment}

This study comes as part of a long investigative research project through a cooperation agreement between two partners, Swiss TPH in Switzerland and NNU in Palestine. NNU contributed in assisting different fieldwork activities. The Swiss Federation through the Swiss Government Excellence Scholarships for Foreign Scholars is also acknowledged for providing the stipend of the principal investigator. Finally, we thank Doris Tranter, a freelancer editor, and Lukas Meier, from Swiss TPH, who contributed to the linguistic revision of the manuscript.

\section{References}

1. Bowsher G, Papamichail A, El Achi N, Ekzayez A, Roberts B, Sullivan R, et al. A narrative review of health research capacity strengthening in low and middle-income countries: lessons for conflict-affected areas. Glob Health. 2019;15. doi:10.1186/s12992-019-0465-y.

2. Tagoe N, Molyneux S, Pulford J, Murunga Vl, Kinyanjui S. Managing health research capacity strengthening consortia: a systematised review of the published literature. BMJ Glob Health. 2019;4:e001318.

3. Senkubuge F, Mayosi BM. The state of the National Health Research system in South Africa: Leadership and governance. 2012.

4. World Health Organization. The WHO strategy on research for health. Geneva: World Health Organization; 2012. 
5. Kirigia JM, Ota MO, Motari M, Bataringaya JE, Mouhouelo P. National health research systems in the WHO African Region: current status and the way forward. Health Res Policy Syst. 2015;13. doi:10.1186/s12961-015-0054-3.

6. Pang T, Sadana R, Hanney S, Bhutta ZA, Hyder AA, Simon J. Knowledge for better health: a conceptual framework and foundation for health research systems. Bull World Health Organ. 2003;81:815-20.

7. Pang T, Sadana R, Hanney S, Bhutta ZA, Hyder AA, Simon J. Knowledge for better health: a conceptual framework and foundation for health research systems. Bull World Health Organ. 2003;81:815-20.

8. National Health Research Systems: report of an international workshop. Geneva: World Health Organization; 2001.

9. Kennedy A, IJsselmuiden C. Building and strengthening national health research systems. A manager's guide to developing and managing effective health research systems. 2006.

http://www.cohred.org/downloads/cohred_publications/NHRS_Assessment_manual_review_version_FINAL.pdf. Accessed 16 Feb 2018.

10. Lee-Martin S, Sadana R, Lee J. Health Research System Analysis (HRSA) Initiative: Methods for Collecting Benchmarks and Systems Analysis Toolkit. 2006.

11. Ismail SA, McDonald A, Dubois E, Aljohani FG, Coutts AP, Majeed A, et al. Assessing the state of health research in the Eastern Mediterranean Region. J R Soc Med. 2013;106:224-33.

12. Hyder A, Syed S, Puvanachandra P, Bloom G, Sundaram S, Mahmood S, et al. Stakeholder analysis for health research: Case studies from low- and middle-income countries. Public Health. 2010;124:159-66.

13. Lairumbi GM, Parker M, Fitzpatrick R, Mike EC. Stakeholders understanding of the concept of benefit sharing in health research in Kenya: a qualitative study. BMC Med Ethics. 2011;12:20.

14. Boyd A, Cole DC, Cho D-B, Aslanyan G, Bates I. Frameworks for evaluating health research capacity strengthening: a qualitative study. Health Res Policy Syst. 2013;11:46.

15. AlKhaldi M, Abed Y, Pfeiffer C, Haj-Yahia S, Alkaiyat A, Tanner M. Assessing policy-makers', academics' and experts' satisfaction with the performance of the Palestinian health research system: a qualitative study. Health Res Policy Syst. 2018;16. doi:10.1186/s12961-0180341-x.

16. AlKhaldi M, Alkaiyat A, Abed Y, Pfeiffer C, Halaseh R, Salah R, et al. The Palestinian health research system: who orchestrates the system, how and based on what? A qualitative assessment. Health Res Policy Syst. 2018;16. doi:10.1186/s12961-018-0347-4.

17. AlKhaldi M, Abed Y, Pfeiffer C, Haj-Yahia S, Alkaiyat A, Tanner M. Understanding the concept and importance of the health research system in Palestine: a qualitative study. Health Res Policy Syst. 2018;16. doi:10.1186/s12961-018-0315-z.

18. Franzen SRP, Chandler C, Lang T. Health research capacity development in low and middle income countries: reality or rhetoric? A systematic meta-narrative review of the qualitative literature. BMJ Open. 2017;7:e012332.

19. Ghaffar DA, IJsselmuiden C, Zicker F. Changing mindsets: Research capacity strengthening in low-and middle-income countries. Council on Health Research for Development (COHRED) Geneva; 2008.

20. Lansang M, Dennis R. Building capacity in health research in the developing world. WHO. 2004;82:764-70.

21. Davey S, International Conference on Health Research and Development, International Conference on Health Research and Development. The report on helath research 2001-2002: health research and global security, overview of the global forum, governance of health research, progress in priority-setting, priorities in helath research, monitoring financial flows, research capacity strengthening, networks in priorityresearch areas. Geneva: Global Forum for Health Research; 2002.

22. Kilic B, Phillimore P, Islek D, Oztoprak D, Korkmaz E, Abu-Rmeileh N, et al. Research capacity and training needs for non-communicable diseases in the public health arena in Turkey. BMC Health Serv Res. 2014;14. doi:10.1186/1472-6963-14-373.

23. Vasquez E, Hirsch JS, Giang LM, Parker RG. Rethinking health research capacity strengthening. Glob Public Health. 2013;8 0 1:S104-24.

24. Sweileh WM, Zyoud SH, Al-Khalil S, Al-Jabi SW, Sawalha AF. Assessing the scientific research productivity of the Palestinian higher education institutions: A case study at An-Najah National University, Palestine. SAGE Open. 2014;4:2158244014544287.

25. Haj Daoud A, Abu Saleh A, Khatib I, Mimi O, Akra I, Zahran S. Scientific Research in Palestine. Research. Palestine: Palestine Academy for Science and Technology; 2002.

http://www.palestineacademy.org/main/images/stories/Pdf/Publications/Survey\%20of\%20Research\%20in\%20Palestine\%20English.pdf. Accessed 16 Feb 2018.

26. Albarqouni L, Abu-Rmeileh NM, Elessi K, Obeidallah M, Bjertness E, Chalmers I. The quality of reports of medical and public health research from Palestinian institutions: a systematic review. BMJ Open. 2017;7. doi:10.1136/bmjopen-2017-016455.

27. WHO. Seven principles for strengthening research capacity in low- and middle-income countries: simple ideas in a complex world. 2014. http://www.who.int/tdr/publications/Essence_report2014_OK.pdf?ua=1. Accessed 16 Feb 2018. 
28. IJsselmuiden C, Jacobs M. Health research for development: making health research work ... for everyone. Scand J Public Health. 2005;33:329-33.

29. Lee K, Mills A. Strengthening governance for global health research. BMJ. 2000;321:775-6.

30. Sadana R, Pang T. Current approaches to national health research systems analysis: a brief overview of the WHO health research system analysis initiative. Cienc Saude Coletiva. 2004;9:351-362.

31. Kennedy A, Khoja TA, Abou Zeid AH, Ghannem H, IJsselmuiden C. National health research system mapping in 10 Eastern Mediterranean countries. EMHJ-East Mediterr Health J 143 502-517 2008. 2008.

32. Hanney S, Kuruvilla S, Soper B, Mays N. Who needs what from a national health research system: lessons from reforms to the English Department of Health's R\&D system. Health Res Policy Syst. 2010;8:11.

33. Decoster K, Appelmans A, Hill P. A Health Systems Research mapping exercise in 26 low-and middle-income countries: narratives from health systems researchers, policy brokers and policy-makers. Backgr Pap Comm Alliance Health Policy Syst Res Dev WHO Health Syst Res Strategy Alliance Health Policy Syst Res. 2011.

34. Scully T. Report tracks standard of research in Middle East - News - Nature Middle East. 2011. https://www.natureasia.com/en/nmiddleeast/article/10.1038/nmiddleeast.2011.29. Accessed 19 Apr 2019.

35. El-Jardali F, Lavis JN, Ataya N, Jamal D. Use of health systems and policy research evidence in the health policymaking in eastern Mediterranean countries: views and practices of researchers. Implement Sci IS. 2012;7:2.

36. COHRED. Visibility of Arab countries in the world biomedical literature. Libyan J Med. 2011;6:6325.

37. Smith E, Haustein S, Mongeon P, Shu F, Ridde V, Larivière V. Knowledge sharing in global health research - the impact, uptake and cost of open access to scholarly literature. Health Res Policy Syst. 2017;15. doi:10.1186/s12961-017-0235-3.

38. World Health Organization, editor. Implementation research toolkit: workbook. Geneve: World Health Organization; 2014.

39. Aljeesh Y, Al-Khaldi M. EMBEDDING HEALTH RESEARCH FINDINGS INTO POLICY MAKING: POLICYMAKERS AND ACADEMICIANS PERSPECTIVE. European Scientific Journal. 2014;:368-80.

40. WHO | What is Evidence-Informed Policy-making and EVIPNet? WHO. http://www.who.int/evidence/about/en/. Accessed 19 Apr 2019.

41. Khoddam H, Mehrdad N, Peyrovi H, Kitson AL, Schultz TJ, Athlin AM. Knowledge translation in health care: a concept analysis. Med J Islam Repub Iran. 2014;28:98.

42. Armstrong R, Waters E, Dobbins M, Anderson L, Moore L, Petticrew M, et al. Knowledge translation strategies to improve the use of evidence in public health decision making in local government: intervention design and implementation plan. Implement Sci IS. 2013;8:121.

43. Kirigia JM, Pannenborg CO, Amore LGC, Ghannem H, IJsselmuiden C, Nabyonga-Orem J. Global Forum 2015 dialogue on “From evidence to policy - thinking outside the box": perspectives to improve evidence uptake and good practices in the African Region. BMC Health Serv Res. 2016;16. doi:10.1186/s12913-016-1453-z.

44. Orem JN, Mafigiri DK, Nabudere H, Criel B. Improving knowledge translation in Uganda: more needs to be done. Pan Afr Med J. 2014;17 Suppl 1. doi:10.11694/pamj.supp.2014.17.1.3482.

45. El-Jardali F, Lavis JN, Ataya N, Jamal D, Ammar W, Raouf S. Use of health systems evidence by policymakers in eastern mediterranean countries: views, practices, and contextual influences. BMC Health Serv Res. 2012;12:200.

46. Bowen S, Erickson T, Martens PJ, Crockett S. More Than "Using Research": The Real Challenges in Promoting Evidence-Informed DecisionMaking. Healthc Policy. 2009;4:87-102.

47. The utilisation of health research in policy-making: concepts, examples and methods of assessment. https://www.ncbi.nlm.nih.gov/pmc/articles/PMC151555/. Accessed 19 Apr 2019.

48. El-Jardali F, Makhoul J, Jamal D, Ranson MK, Kronfol NM, Tchaghchagian V. Eliciting policymakers' and stakeholders' opinions to help shape health system research priorities in the Middle East and North Africa region. Health Policy Plan. 2010;25:15-27.

49. McMaster University and Public Health Agency of Cana. Building capacity for evidence-informed public health: A Model for EvidenceInformed Decision Making in Public Health.

https://www.nccmt.ca/uploads/media/media/0001/01/4504c27e14836059b8fd3ce3b3eaac2ed2ce6ed6.pdf. Accessed 19 Apr 2019.

\section{Tables}

\section{1: HR Quality and Standardization (HRQS)}




\begin{tabular}{|c|c|c|c|}
\hline \multicolumn{4}{|c|}{ HR Quality and Standardization (HRQS) } \\
\hline $\begin{array}{l}\text { Theme } \\
\text { Sector }\end{array}$ & Theme 1: The status of HRQS & Theme 2: Limiting the HRQS & $\begin{array}{c}\text { Theme 2: Enhancing the } \\
\text { HRQS }\end{array}$ \\
\hline Gov. & $\begin{array}{l}\text { - It is standardized and HR actors } \\
\text { are qualified } \\
\text { - Most of HR meets the international } \\
\text { HRQS } \\
\text { - We have a quality education system } \\
\text { - HR is of high quality, standardized, } \\
\text { and meets HRQS } \\
\text { - Some HR meets the international } \\
\text { standardization when it gets } \\
\text { published in high impact factor } \\
\text { - HR relies on international } \\
\text { standardization endorsed by WHO, } \\
\text { but we cannot say that it is } \\
\text { efficient and standardized } \\
\text { - We attempt to meet the HRQS } \\
\text { - Barely meets the HRQS criteria, } \\
\text { some researchers do high-quality } \\
\text { research. We have a lot of HR } \\
\text { published internationally } \\
\text { - At the publishing stage yes where } \\
\text { international journals have } \\
\text { rigorous guidelines } \\
\text { - HRQS on an average level and } \\
\text { only for promotions } \\
\text { - In fact, I don't know and it is hard } \\
\text { to judge } \\
\text { - No, every university has different } \\
\text { ways of HR }\end{array}$ & $\begin{array}{l}\text { - Unsupportive environment and culture, } \\
\text { poor capacity building programmes, } \\
\text { weakness of school curriculum, the } \\
\text { absence of clear policies and agreed } \\
\text { priorities } \\
\text { - Our abilities, experiences and will are very } \\
\text { limited } \\
\text { - Inadequate funding } \\
\text { - Lack of experts in HR } \\
\text { - Shortage of data that observe the national } \\
\text { productivity of HR } \\
\text { - HR time, effort and cost } \\
\text { - Lack of specialized national HR centre }\end{array}$ & $\begin{array}{l}\text { - Addressing carefully } \\
\text { these gaps } \\
\text { - Need more budgets, } \\
\text { good HR management, } \\
\text { coordination among all } \\
\text { stakeholders } \\
\text { - Capacities and } \\
\text { experiences need to be } \\
\text { empowered } \\
\text { - Encourage academic } \\
\text { exchange programmes } \\
\text { with others } \\
\text { - Self-development, } \\
\text { sufficient resources, and } \\
\text { political support } \\
\text { - Formulate laws and } \\
\text { effective policies will } \\
\text { increase our HR quality } \\
\text { - Education programmes } \\
\text { in scientific research }\end{array}$ \\
\hline Acad. & $\begin{array}{l}\text { - Yes, academia has high quality and } \\
\text { reaches intern. guidelines } \\
\text { - Not a lot but some HR performed } \\
\text { with good quality } \\
\text { - We often publish properly } \\
\text { - There are some good HR with high } \\
\text { quality, generally, HR has a } \\
\text { moderate quality and high quality } \\
\text { often done by foreign co-authors } \\
\text { - Relatively, we have researchers } \\
\text { produce HR with good quality } \\
\text { - HR quality is variable, some are } \\
\text { good and some bad } \\
\text { - Majority HR has poor quality with } \\
\text { a huge gap with the international } \\
\text { guidelines } \\
\text { - Our HR quality is not good enough } \\
\text { despite many good publications } \\
\text { - Quality is low and not comparable } \\
\text { with international standardization } \\
\text { - No clear national policy includes } \\
\text { guidelines } \\
\text { - No, HR production is very low } \\
\text { quality and quantity, does not meet } \\
\text { HRQS }\end{array}$ & $\begin{array}{l}\text { - Noncompliance with the international HR } \\
\text { guidelines } \\
\text { - Brain drain and time constraint } \\
\text { - HR performed for personal purposes } \\
\text { - Lack of resources and infrastructure } \\
\text { - HR plagiarism and researchers bias } \\
\text { - Weak researchers competencies and skills } \\
\text { in different research expertise } \\
\text { - Gaps in HR design, methods, analysis, data } \\
\text { quality, and interpretation } \\
\text { - Lack of international experiences } \\
\text { - Lack of fund and official sponsorship } \\
\text { - Lack of good journal accessibility } \\
\text { - Lack of experimental HR } \\
\text { - Lack of centres of excellence } \\
\text { - Lack of HRQS monitoring } \\
\text { - A gap in the schools' curriculum }\end{array}$ & $\begin{array}{l}\text { - A good investment in HR } \\
\text { productivity } \\
\text { - Allocate appropriate } \\
\text { financial support and } \\
\text { resources } \\
\text { - Overcome plagiarism } \\
\text { and promote HR } \\
\text { objectivity } \\
\text { - HR should be focusing } \\
\text { on priorities } \\
\text { - Systematic capacity } \\
\text { building programmes to } \\
\text { develop HR leaders', } \\
\text { experts', and } \\
\text { postgraduates' } \\
\text { skills in research critical } \\
\text { thinking, design, writing } \\
\text { and publication } \\
\text { - Pay attention to the } \\
\text { international orientation } \\
\text { to exchange knowledge } \\
\text { and expertise } \\
\text { - Effective HR policies } \\
\text { addressing HRQS }\end{array}$ \\
\hline & $\begin{array}{l}\text { - HR is conducted in good quality } \\
\text { but still weak against intern. } \\
\text { standard } \\
\text { - It is satisfying, high quality, and } \\
\text { based on scientific methods } \\
\text { - HR quality is improving and has a } \\
\text { long way to go } \\
\text { - Some quality exists but } \\
\text { researchers striving to get high } \\
\text { quality }\end{array}$ & $\begin{array}{l}\text { - HR is unsystematic and lack of strategic HR } \\
\text { policies or unified body } \\
\text { - Shortage of resources and facilities } \\
\text { - Low researchers qualities and skills } \\
\text { - Inattention and unwillingness to HR } \\
\text { - Quality data but disorganized, unanalyzed } \\
\text { and not used in practice } \\
\text { - Discontinuity of the HR process } \\
\text { - Lack of orientation and linkage with the } \\
\text { international HR } \\
\text { - Lack of local high-impact journals }\end{array}$ & $\begin{array}{l}\text { More exposure to the } \\
\text { international HR } \\
\text { experiences } \\
\text { Investment in LPHA to } \\
\text { expand our HR capacity } \\
\text { and expertise } \\
\text { - Research teams are } \\
\text { essential } \\
\text { HR should meet the local } \\
\text { needs }\end{array}$ \\
\hline
\end{tabular}


- It is varying but HR quality is a real problem and still perceived weak

- HR is not of high quality yet and does not meet international guidelines

- Poor quality, it needs more improvement

- An immense number of HR with a lack of quality

- We still have not reached the required HR quality

- Never, but some individual attempts having reached the quality exist
- A weakness of institutional research review - HR duplication

- A gap in the education curriculum of the health professions

- HR performs for individual not society goals
An annual national forum for $\mathrm{HR}$

Dynamic HR monitoring and evaluation system in Palestine Unifying the HR concepts, methods, priorities, practices, uses and guidelines.

Promote the use of communication and technology

Capacity building programmes in HR concepts, methods, and good practices

\section{2: HR Knowledge Transfer and Dissemination (HRKTD)}


HR Knowledge Transfer and Dissemination (HRKTD)

\begin{tabular}{|c|c|c|c|}
\hline $\begin{array}{l}\text { Theme } \\
\text { Sector }\end{array}$ & $\begin{array}{c}\text { Theme 1: Limiting factors of } \\
\text { HRKTD }\end{array}$ & Theme 2: Enhancing factors of HRKTD & Theme 3: Opportunities to build on \\
\hline Gov. & $\begin{array}{l}\text { - Lack of a unified system and - } \\
\text { policy and HRKTD tools (e.g. } \\
\text { journals and periodicals) with } \\
\text { lack of advanced technology } \\
\text { infrastructure } \\
\text { - Weak recognition and immature } \\
\text { sharing culture } \\
\text { - No specific central HRKTD } \\
\text { platform with selective } \\
\text { unsystematic HRKTD and } \\
\text { unclear roles } \\
\text { - Miscommunication and lack of } \\
\text { coordination and cooperation } \\
\text { - Data inaccessible and } \\
\text { unsystematic } \\
\text { - Limited HRKTD at micro- } \\
\text { institutional while absent at the } \\
\text { macro-national level with HR } \\
\text { redundancy and discontinuity } \\
\text { - Disregard to share HR outputs } \\
\text { with personal desires } \\
\text { - Officials' inattention to use HR } \\
\text { as a decision-making tool } \\
\text { - HR from academia is not } \\
\text { disseminated and unexploited } \\
\text { - Lack of intellectual integrity and } \\
\text { rights } \\
\text { - Conducted HR is rarely needs- } \\
\text { driven } \\
\text { - Lot of descriptive HR and weak } \\
\text { applied HR and deficit of } \\
\text { specialized HR (surgery, internal } \\
\text { medicine, etc.) }\end{array}$ & $\begin{array}{l}\text { Effective HRKTD and } \\
\text { communication mechanisms, solid } \\
\text { political will, and rewarding } \\
\text { measures } \\
\text { - Integral-institutionalized system by } \\
\text { activating a unified body and } \\
\text { building HR strategy } \\
\text { - Resources and incentives are needed } \\
\text { - Divide stakeholders' roles } \\
\text { - Raise the awareness of HRKTD } \\
\text { - Real C\&C should be enhanced and } \\
\text { promote a national scientific-policy } \\
\text { dialogue between researchers and } \\
\text { decision-makers } \\
\text { - A need for an effective and reliable } \\
\text { central computerized information } \\
\text { system } \\
\text { - Allocate sufficient resources }\end{array}$ & $\begin{array}{l}\text { Plenty of published and unpublished } \\
\text { HR } \\
\text { Certain connections and } \\
\text { cooperation } \\
\text { Well-developed health information } \\
\text { unit which has a good collecting } \\
\text { method } \\
\text { LPHA and PNIPH presence } \\
\text { Excellent students and experts } \\
\text { Some respectable HRKTD } \\
\text { academia attempts }\end{array}$ \\
\hline Acad. & $\begin{array}{l}\text { - The absence of HRKTD } \\
\text { mechanisms } \\
\text { - HR either for personal interests } \\
\text { or getting funding } \\
\text { - HRKTD is only limited to } \\
\text { workshops and conferences } \\
\text { without a well-informed DM } \\
\text { - Publication incompetence and } \\
\text { cost, time limit and academic } \\
\text { overloads to perform HRKTD } \\
\text { - Uncompleted researchers' role } \\
\text { with lots of unpublished, not } \\
\text { disseminated and underutilized } \\
\text { HR } \\
\text { - Resources and fund } \\
\text { insufficiency } \\
\text { - Communication gaps and } \\
\text { researchers are not involved in } \\
\text { the decision-making } \\
\text { - Unreliable, inaccessible and not } \\
\text { well-analyzed data which is } \\
\text { descriptive and lack of local } \\
\text { good journal } \\
\text { - Some HRKTD performed for } \\
\text { graduation or personal needs } \\
\text { - The difficulty for decision- } \\
\text { makers to read and understand } \\
\text { English publications and } \\
\text { knowledge } \\
\text { - Decision-makers are not } \\
\text { interested in evidence }\end{array}$ & $\begin{array}{l}\text { - Coordination, partnership, teaming } \\
\text { up, and agreed vision and policies } \\
\text { - Incentives focus on HR quality, } \\
\text { credibility, publication and HRKTD } \\
\text { abilities } \\
\text { - HRKTD platform or communication } \\
\text { such Knowledge for policy (K4P), } \\
\text { agreed database, encourages } \\
\text { dialogue and research-decision } \\
\text { making the linkage } \\
\text { - More investment on HRKTD, and a } \\
\text { supervisory inclusive body } \\
\text { - PNIPH to lead a proper HRKTD } \\
\text { - Institutional HRKTD means and } \\
\text { encourages Arabic publications and } \\
\text { specialized conferences } \\
\text { - Decision-makers involvement in HR } \\
\text { and supportive climate and HR } \\
\text { centres with information accessibility } \\
\text { (e.g libraries, labs, training) } \\
\text { - Awareness of role-playing in HR and } \\
\text { train human resources in HRKTD }\end{array}$ & $\begin{array}{l}\text { Good HRKTD by many academic } \\
\text { institutions } \\
\text { A critical function to get decisions } \\
\text { informed by evidence } \\
\text { Some universities implemented } \\
\text { campaigns on HRKTD } \\
\text { Plenty of HR } \\
\text { PNIPH could be an HRKTD } \\
\text { platform } \\
\text { Human resources with good } \\
\text { potentials } \\
\text { WHO and private sector funding } \\
\text { role }\end{array}$ \\
\hline
\end{tabular}




\begin{tabular}{|c|c|c|c|}
\hline & $\begin{array}{l}\text { - Lack of role-play culture among } \\
\text { producers and users } \\
\text { - Policy-makers' reliance on } \\
\text { internal reports }\end{array}$ & & \\
\hline NGOs & $\begin{array}{l}\text { - Lack of a regulating body, } \\
\text { leadership, and HR credibility } \\
\text { and quality } \\
\text { - Selective HRKTD not inclusive } \\
\text { with lack of linkages and } \\
\text { coordination among producers } \\
\text { and users and institutions } \\
\text { - Lack of local high-impact } \\
\text { journals (e.g Arabic), decent } \\
\text { conference, and libraries } \\
\text { - Inattention to read HR findings } \\
\text { - Researchers' incomplete role in } \\
\text { HRKTD } \\
\text { - Poor roles of MOH to lead and } \\
\text { academia to feed } \\
\text { - Disorganized, inaccessible, and } \\
\text { monopoly of database } \\
\text { - Lack of structured and agreed } \\
\text { HRKTD platform } \\
\text { - International connections are } \\
\text { limited } \\
\text { - Blockage, political conditions, } \\
\text { and individual desires and } \\
\text { donors interests impede HRKTD } \\
\text { - Lack of publication competence } \\
\text { and writing an informative } \\
\text { policy analysis }\end{array}$ & $\begin{array}{l}\text { - MOH should establish a clear } \\
\text { governance structure and policy } \\
\text { (HRKTD committee) to ensure } \\
\text { effective decision-making based on } \\
\text { HR } \\
\text { - More attention to HRKTD and HR } \\
\text { importance and evaluation } \\
\text { - Promote team working and } \\
\text { coordination and cooperation } \\
\text { - Set a dynamic and structured } \\
\text { HRKTD platform, use technology and } \\
\text { encourage policy dialogue } \\
\text { - Annual expanded Congress to share } \\
\text { all relevant national HR outputs } \\
\text { - The scientific publication needs to be } \\
\text { encouraged }\end{array}$ & $\begin{array}{l}\text { Medical Aid for Palestinians (MAP- } \\
\text { UK)- Institute of Community and } \\
\text { Public Health (ICPH) partnership in } \\
\text { LPHA as the best platform for } \\
\text { HRKTD } \\
\text { High experts and international } \\
\text { agencies } \\
\text { Advanced technology and distance } \\
\text { learning } \\
\text { International publications by local } \\
\text { researchers } \\
\text { Local conferences }\end{array}$ \\
\hline
\end{tabular}

Table 3: Health Research Translation and Utilization into Decisions and Policies (HRTUDP) 


\begin{tabular}{|c|c|c|c|}
\hline \multicolumn{4}{|c|}{ Health Research Translation and Utilization into Decision and Policies (HRTUDP) } \\
\hline Theme & Theme 1: Limiting factors of HRTUDP & $\begin{array}{c}\text { Theme 2: Improving factors of } \\
\text { HRTUDP }\end{array}$ & $\begin{array}{l}\text { Theme 3: Opportunities to } \\
\text { build on }\end{array}$ \\
\hline Sector & & & \\
\hline Gov. & $\begin{array}{l}\text { - Each entity has its own evidence without } \\
\text { sharing them with others with poor culture } \\
\text { and attitude on HR } \\
\text { - Financial shortage and poor qualification } \\
\text { - Gaps in sectorial coordination, } \\
\text { communication, and conflicting interests } \\
\text { among producers and users } \\
\text { - Ineffective evidence and knowledge } \\
\text { dissemination, researchers do not share their } \\
\text { results } \\
\text { - State management changes hinder HR } \\
\text { translation } \\
\text { - Policy-makers preoccupation to read policy } \\
\text { briefs with poor quality of HR } \\
\text { - A plethora of unused information and } \\
\text { knowledge } \\
\text { - Plenty of descriptive HR rather than } \\
\text {-xperiment } \\
\text { - The absence of common body implements } \\
\text { HR outputs }\end{array}$ & $\begin{array}{l}\text { - Agreed policy, coordination, } \\
\text { and agreed priorities for results } \\
\text { application } \\
\text { - Acad. and Gov. communication } \\
\text { and developing researchers } \\
\text { capacity } \\
\text { - Reactivate journals clubs to } \\
\text { review HR findings to be utilized } \\
\text { - Decision-makers must be } \\
\text { convinced of HR evidence in } \\
\text { planning and decision-making } \\
\text { - Awareness of evidence-based } \\
\text { decision-making } \\
\text { - Systematic policy workshops } \\
\text { discuss all implemented } \\
\text { research } \\
\text { - Clear and regular policy briefs } \\
\text { to decision-making and planning } \\
\text { bodies }\end{array}$ & $\begin{array}{l}\text { - PNIPH existence and role } \\
\text { to take this mandate } \\
\text { - SPHC can play an } \\
\text { important role }\end{array}$ \\
\hline Acad. & $\begin{array}{l}\text { - Schools' HR outputs are untapped and } \\
\text { unused with ineffective dissemination among } \\
\text { departments } \\
\text { - HRTUDP is not a methodology of state } \\
\text { policy-making with lack of policy-makers' } \\
\text { research orientation and their dependency } \\
\text { on political inputs rather than evidence } \\
\text { enforced by political and donors' agendas } \\
\text { - No transparency and immaturity of } \\
\text { Evidence-based practices (EBPs) culture } \\
\text { with limited resources } \\
\text { - Lack of communication between researchers } \\
\text { and decision-makers due to unshared } \\
\text { knowledge through clear interpreted findings } \\
\text { - Unpublished HR, HR not priorities-based and } \\
\text { not health system needs-oriented } \\
\text { - Time limitation to academics for } \\
\text { dissemination } \\
\text { - NGOs are dependent and subject to the } \\
\text { donors' wills } \\
\text { - Lack of experimental studies and HR quality } \\
\text { and credibility is an issue } \\
\text { - HR does not address health improvement } \\
\text { and is mainly personal-interest driven } \\
\text { - Health actions are spontaneously performed } \\
\text { not based on HR with contradiction goals in } \\
\text { obtaining the funding }\end{array}$ & $\begin{array}{l}\text { - An integrated system adopts the } \\
\text { HR routine translation process } \\
\text { and urges decision-makers to be } \\
\text { research-oriented and develop } \\
\text { their capacities in EBPs } \\
\text { - Researchers' and policy-makers' } \\
\text { communication and involvement } \\
\text { for effective, efficient and timed } \\
\text { translation into decision-making } \\
\text { - Training capacity building to } \\
\text { raise awareness and improve } \\
\text { skills on HRTUDP } \\
\text { - Encourage dissemination } \\
\text { through organizational plan } \\
\text { supported by a high national } \\
\text { scientific HR body } \\
\text { - New policies dedicated to EBPs } \\
\text { and collaborative work to } \\
\text { involve all players on how to } \\
\text { translate evidence into decision- } \\
\text { making } \\
\text { - Sectorial research-policymaking } \\
\text { coordination and cooperation } \\
\text { based on agreed priorities in } \\
\text { research topics selection, } \\
\text { conduction, and dissemination }\end{array}$ & $\begin{array}{l}\text { - Successful attempts which } \\
\text { are evidence-based (such } \\
\text { as non-communicable } \\
\text { diseases screening) } \\
\text { - WHO explicit role to } \\
\text { develop HRS and seize } \\
\text { Lancet annual meetings } \\
\text { - Without evidence-based } \\
\text { decisions (EBDs), big } \\
\text { losses, e.g. waste } \\
\text { resources, unimproved } \\
\text { health, and incorrect } \\
\text { decisions will rise } \\
\text { - Health system and care } \\
\text { will be met and improved } \\
\text { - Birziet University and } \\
\text { LPHA achieved some } \\
\text { success }\end{array}$ \\
\hline NGOs & $\begin{array}{l}\text { - Lack of policy-makers' awareness and } \\
\text { interest in HR } \\
\text { - Lack of clear HR system and agreed HR } \\
\text { priorities and policy } \\
\text { - Unmonitored decision-making and lack of } \\
\text { policy informing and briefing skills with poor } \\
\text { communication and dissemination among } \\
\text { stakeholders } \\
\text { - Produced evidence does not reflect the } \\
\text { national priorities and it not connected to the } \\
\text { society's needs } \\
\text { - Lack of HR quality and data credibility } \\
\text { - The negative impact of social, political and } \\
\text { economic instability on decision-making } \\
\text { - HR is a personal interest with no influence } \\
\text { on decision-making }\end{array}$ & $\begin{array}{l}\text { - A clear structure to guide HR, } \\
\text { foster knowledge transfer and } \\
\text { translation, a solid link between } \\
\text { researchers and policy-makers } \\
\text { - MoH should embrace EBDs in } \\
\text { policy-making processes } \\
\text { - Support to encourage human } \\
\text { resources } \\
\text { - A body to implement evidence } \\
\text { translation, local-international } \\
\text { networks to benefit from their } \\
\text { experience and to get } \\
\text { accessibility } \\
\text { - Politic tensions should be } \\
\text { separated from development } \\
\text { decisions }\end{array}$ & $\begin{array}{l}\text { - Major improvements in } \\
\text { post- and ante-natal care } \\
\text { are based on evidence } \\
\text { - PNIPH to lead improving } \\
\text { EBPs and knowledge } \\
\text { transfer } \\
\text { - Utilizing the presence of } \\
\text { SRC }\end{array}$ \\
\hline
\end{tabular}


- Most of HR done in health schools is neglected and unutilized

- The inability of state legislative boards to use $\mathrm{HR}$ findings in their decision-making, good

HR selection is an issue

- The abundance of evaluative and statistical studies with a deficit of experimental ones
- Partnerships provide empowerment programmes, allocate resources, academiastate integration

- HR culture should be enhanced and integrated into the decisionmaking process

- All health interventions need to be based on evidence and aligned with HR priorities 